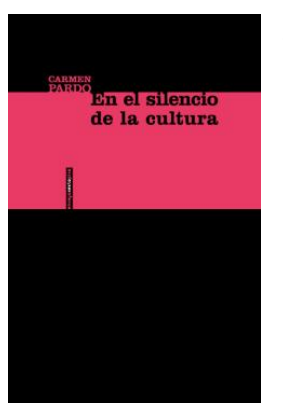

Carmen Pardo (2016).

En el silencio de la cultura. Madrid / México: Sexto Piso.

ISBN: 978-84-163558-94-6

\title{
Iván Sánchez-Moreno
}

Universitat de Barcelona; ivan.samo@gmail.com

La tenebrosa imagen de Saturno devorando a sus hijos nos ilustra el tono de las reflexiones de Carmen Pardo nada más empezar la lectura de su último y delicioso libro. Entre pasajes de elevada carga poética, la autora nos sumerge en varios fenómenos sociales acaecidos durante el siglo XX que ponen de manifiesto el pernicioso -por consentido- asentamiento de la banalización cultural del mundo.

El silencio al que alude el título de su obra remite sobre todo a la indiferencia ante la guerra a la que los medios nos tienen ya preocupantemente demasiado acostumbrados, a lo que contribuye de modo especial su descarado mercantilismo popular. Como ejemplifica Pardo con la Historia del soldado de Stravinsky, la rápida habituación al ruido de las bombas y las metralletas desde principios del siglo pasado acabó por trastocar -incluso ensordecer- nuestra propia sensibilidad musical, dando por triste resultado un paulatino empobrecimiento de las melodías, una mayor preeminencia de los ritmos y una patética reducción del matiz orquestal. Al respecto, abundarán en este libro los recursos musicales considerando que Carmen Pardo, experta en la obra de John Cage -como prueban La escucha oblicua (2014) y la edición de Escritos al oído (1999), entre otros trabajos-, es profesora de Historia de la Música en la Universitat de Girona y profesora en un máster de Arte Sonoro.

También serán numerosas las referencias a la historia de la psicología, disciplina que -a su pesar- asomará repetidas veces a lo largo de las 255 páginas de este provocador ensayo. En el silencio de la cultura nos brinda una sutil lectura transversal de cómo la psicología influyó -para mal- en esta desensibilización sistemática de la humanidad frente a los crímenes masivos de la guerra. Los cuatro grandes capítulos que

Sánchez, Ivan (2017). Reseña de Pardo (2016) En el silencio de la cultura. Athenea Digital, 17(3), 279283. http://dx.doi.org/10.5565/rev/athenea.2177 
contiene el libro podrían muy bien reintegrarse en una estructura tripartita que se inicie con un primer bloque centrado en las estrategias y técnicas de biopoder en las que la psicología desempeñó un papel capital. Los métodos de condicionamiento de las masas y la criminalización de ciertos sectores de la población son claros ejemplos de estas prácticas sociales desde finales del siglo XIX. En una segunda parte de En el silencio de la cultura se refieren cuantiosas evidencias de dichas contribuciones de la psicología al campo bélico. Los dos últimos capítulos del libro, en cambio, ofrecen una airada reflexión sobre los cambios éticos y epistemológicos que inspiraron los más recientes giros paradigmáticos de la psicología oficial tras el fin de la II Guerra Mundial.

Según la autora, la desacralización del arte fue uno de los primeros síntomas de la posmodernidad del siglo XX y, por ende, de la pérdida de valores sobre los que se sostenía nuestra cultura desde los más pretéritos tiempos. Cualquiera de los readymade de Duchamp implicaba un cambio de contexto para dotar de nuevo sentido estético a un objeto mundano, como dictaran también los fundamentos del ruidismo, el arte pop o la música electroacústica. Si el primero enardecía la belleza sonora del ambiente bélico, el segundo reducía su filosofía a la mera reproducción de copias a partir de un modelo originario. No es casualidad que el auge del arte pop hallara en la fiebre de las recreaciones musicales un ingente mercado a explotar desde mediados del siglo pasado. Las técnicas de propaganda que se ensayaron durante la guerra fueron posteriormente puestas en práctica para el consumo masivo, como demuestra la significativa venta de juguetes bélicos destinados al público infantil y de un elevado tiraje de novelas románticas ambientadas en las guerras precedentes desde el desmantelamiento de los grandes imperios europeos. De hecho, hoy prospera una nauseabunda estetización de la guerra en la ropa infanto-juvenil y el material escolar que imitan en su estampación los diseños del camuflaje bélico. Conviene recordar que las primeras campañas de reclutamiento de la I Guerra Mundial, consistentes en grandes carteles en los que un alto oficial señalaba directamente al ciudadano de modo inquisitivo con el dedo índice, ya eran en sí un poderoso instrumento de represión social que convertía al propio individuo en un objeto de consumo.

En los períodos de entreguerras el conflicto bélico podía generar tantos dividendos en forma de productos de ocio como en el propio campo de batalla. Carmen Pardo nos remite a ciertas prácticas de la guerra psicológica que se experimentaron durante la I Guerra Mundial y que pronto se reciclaron para una fructífera salida al mercado. Sirva de ejemplo la difusión de películas rodadas en el frente y de fotografías de heridos, mutilados y muertos con el objetivo de desmoralizar al enemigo. En efecto, el morbo movía muchos nuevos sentimientos de placer que invalidaban la responsabilidad y el compromiso moral del consumidor frente a lo que estaba viendo. Desde una 
perspectiva similar, Teodoro Adorno denunció la inversión del ocio cultural en la gestión de las masas, con el fin de controlar su tiempo libre y crear otros nuevos modos de productividad para las personas desocupadas laboralmente. Esta crítica de cariz marxista se basta del atractivo estético por la guerra que mostraba gran parte de las obras surgidas del futurismo, el dadaísmo y el primer surrealismo, así como la progresiva infantilización de una sociedad que, entre otras cosas, llegó a lucrarse con la venta de máscaras antigás con la silueta de Mickey Mouse tras los ataques de Pearl Harbour, según expone Pardo en el tercer capítulo de su libro.

La introducción masiva de la psicología en el ideario popular fue potenciada sobre todo a través de macroeventos culturales como la Exposición Universal de París de 1889, la cual acogió un Congreso Internacional de Antropología Criminal en el que grandes nombres de la historia de la psicología reclamaron su particular protagonismo. Muchos de ellos abrazaron las teorías degeneracionistas de Cesare Lombroso a la hora de dar una explicación científica a la naturaleza anómala del delincuente común. Tissié, por ejemplo, aducía que el debilitamiento del ciudadano medio europeo era debido a la mezcla racial, al tiempo que exigía del ejercicio físico para disciplinar a aquellas personas sentenciadas por haberse desviado del camino moral correcto por la falta de una autoridad paternal durante la infancia. La Völkerpsychologie o psicología de los pueblos también aportó su granito de arena en la constitución de un poderoso sentimiento nacionalista que, sumado a la influencia del credo eugenésico de Francis Galton, propició nuevos métodos de segregación social, así como la selección discriminada y la formación regulada de una potencial soldadesca en caso de una futura guerra.

Pero donde para su desgracia más va a destacar la alianza entre la psicología y el biopoder fue bajo el auspicio del gobierno nacionalsocialista y, más concretamente, en el uso que éste le dio a las tesis degeneracionistas y psicobiologicistas que alumbraron los nuevos criterios estéticos de un gusto musical nacional. Carme Pardo apunta los nombres de Max Nordau, Oswald Koller y el citado Cesare Lombroso entre los principales referentes adoptados por los ideólogos de la estética nazi, cuya influencia asoma sin disimulo en numerosos estudios que pretendían establecer una conexión entre las formas de la música judía y la incapacidad mental para adquirir una sensibilidad armónica, o bien los denodados intentos por erradicar el jazz del gusto popular. La exposición sobre arte degenerado comisariada por Joseph Goebbels se sustentó interesadamente sobre los fundamentos de Emil Kraepelin, Ernst Kretschmer, Hans Prinzhorn y el conde de Gobineau para alinear al jazz y la música atonal al lado del arte insano, primitivo e infantil. Y mientras que el gobierno nazi divulgaba la concepción de la salud como un deber patriótico, se prohibía la crítica artística en todos los países germánicos para pasar a ser gestionada exclusivamente por el Estado alemán. 
Para afianzar su deuda con el régimen, algunos músicos fieles a Hitler tomaron posesión de cargos de primer orden en instituciones culturales de alto copete: así, Richard Strauss ocupó la plaza de presidente de la Cámara de la Música, siendo Wilhelm Furtwängler su principal subalterno; Hitler se reservaría para sí la dirección artística del Festival de Bayreuth, creado para el expreso homenaje de Richard Wagner.

El otro gran compositor encumbrado como adalid ario fue el sordo Beethoven, cuya $9^{a}$ sinfonía fue apropiada por el gobierno nazi como feroz arma propagandística. Tanto fue así que en todos los países ocupados se interpretaba la Oda a la alegría supliendo las funciones de una marcha triunfal, imponiéndose como toda una declaración de intenciones políticas, más que estéticas. La misma utilidad adquirirá la música en los campos de concentración, donde cada uno de los actos que allí se ejecutaban era amenizado con una banda sonora particular, incluyendo las muertes sumariales. El acompañamiento musical no sólo aligeraba la carga dramática de la situación, sino que también influía en el rendimiento del trabajo forzoso, como antes ya se había probado con éxito en fábricas y talleres con el beneplácito de los expertos que estudiaron los efectos de la música sobre la psique humana. La música también se usó con fines conductistas para reeducar la mente de los opositores al sentimiento nacionalista a base de obligarles a cantar en coro los himnos alemanes y las cantatas sacras bajo coacción. El propio Adorno observó algunos elementos escenográficos en los mítines nazis que provocaban en el público asistente efectos similares a la histeria colectiva, tales como los redobles de tambor para subrayar los acentos y las inflexiones de voz del orador, manteniendo activa en todo momento la atención del oyente.

Con el fin de la II Guerra Mundial, la silenciosa sombra de la psicología se hizo ver con los inicios de la cibernética aplicada al diseño inteligente de armamento nuclear en medio mundo. Carmen Pardo se sirve de varias declaraciones de Norbert Wiener para justificar el papel que desempeñó la cibernética en el nacimiento de la escuela cognitiva. Las manifestaciones de Wiener, sin embargo, auguran para la investigación en Inteligencia Artificial un importante peso en el dominio hegemónico de la sociedad a través de nuevos sistemas de gobierno basados en el ¿libre? intercambio de información. El resultado, por el contrario, no escapa a la homogeneización del pensamiento, el establecimiento de un lenguaje común y el registro absoluto de datos de toda la población mundial - no es casualidad que una empresa como IBM colaborase en el conteo de todos los prisioneros de los campos de concentración-.

El último episodio de estulticia masiva de la sociedad actual lo expone Pardo con el ejemplo de la muñeca Barbie. Nacida a partir de la suma de fuerzas entre el mismo ingeniero que diseñó los misiles Sparrow-Hawk y un psicólogo del marketing especializado en motivación, la belleza idealizada que proyecta Barbie hunde sus raíces en 
la eugenesia racial formulada en el siglo XIX. De poco sirvieron los intentos por ridiculizarla llevados a cabo por un grupo de activistas que boicoteó 300 unidades de Barbies parlantes cambiándoles sus circuitos de voz por los de los guerreros G.I.Joe, trastocando así los roles de género de unos y otros. Inmune a las burlas, la modélica y utópica Barbie se ha ido adaptando a los tiempos, hasta el punto de presentarse en 2008 a la presidencia de los EEUU imitando a Hillary Clinton. El gusto humano por parecerse al juguete en cuestión -menos inofensivo políticamente de lo que pueda presumirse $a$ priori por los valores que difunde entre la población civil- es consecuencia del tecnofetichismo que han reivindicado David Cronenberg, J. G. Ballard o H. R. Giger en sus obras respectivas, generando nuevas formas de atracción basadas en las intervenciones plástico-quirúrgicas y el injerto de implantes artificiales que permitan expresar el deseo de mejorar las limitaciones naturales del cuerpo humano. Y todo ello sin asomo alguno de prejuicios, más bien al contrario: piénsese en las prótesis mamarias o los labios de colágeno que aúpan a sus portadoras hasta el estrellato y la fama efímera, por ejemplo.

En el silencio de la cultura no sólo trata sobre la indiferencia pública que legitima las atrocidades del ruido bélico de fondo y la explotación ciudadana a través de los intereses de mercado. El libro de Carmen Pardo también puede (y debe) leerse como un revulsivo crítico para reflexionar sobre importantes cuestiones éticas y epistemológicas sobre el proceder de la psicología en la sociedad. El eco de sus rumores no ha cesado de sonar de fondo desde que Wundt abriera (quizá sin querer) la caja de Pandora en aquel vetusto laboratorio en 1879 , sin notar el fétido aliento de Saturno en su propio cogote.

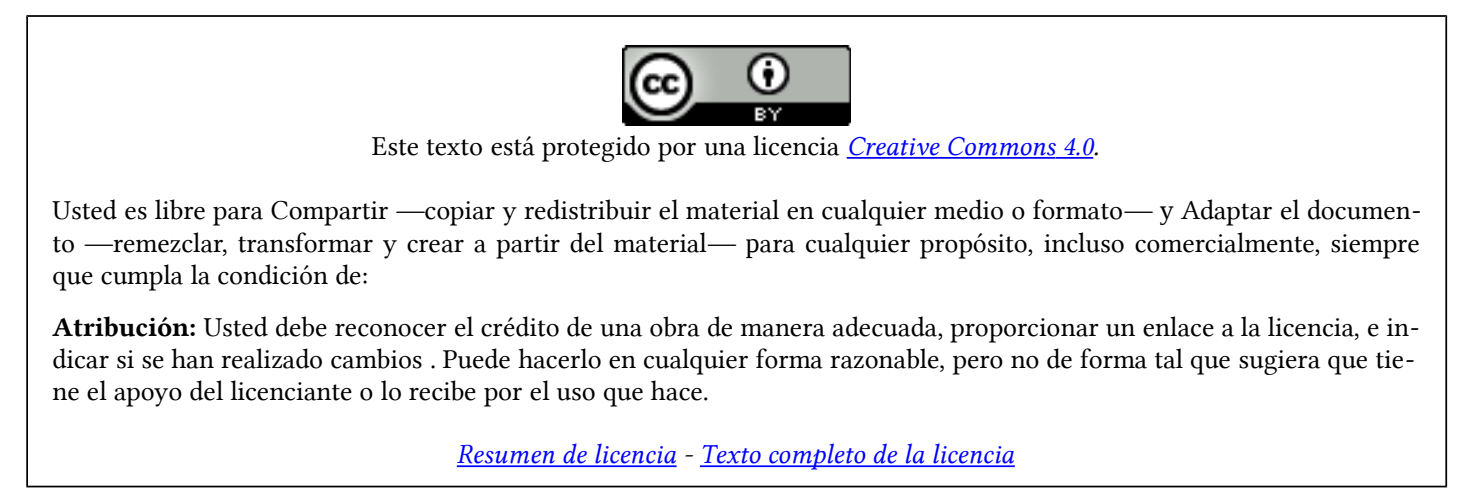

